The Journal of Academic Librarianship, 2007, Vol. 33, No. 2, p.228-242.

ISSN: 0099-1333 (print) 1879-1999(online)

DOI: 10.1016/j.acalib.2006.12.007

http://www.sciencedirect.com/science/journal/00991333/33/2

http://www.sciencedirect.com/science/article/pii/S009913330600228X

Copyright @ 2007 Published by Elsevier Inc

\title{
New Strategies for Delivering Library Resources to Users: Rethinking the Mechanisms in which Libraries are Processing and Delivering Bibliographic Records
}

\author{
by Magda El-Sherbini and Amanda J. Wilson
}

\begin{abstract}
The focus of this paper is to examine the current library practice of processing and delivering information and to introduce alternative scenarios that may keep librarians relevant in the technological era. In the scenarios presented here, the authors will attempt to challenge basic assumptions about the usefulness of and need for OPAC systems, Web OPAC's, OCLC (as one of the major bibliographic utilities), and consortia. The authors then identify ways in which libraries can leverage their resources and available technology to create cost-effective ways of delivering improved services.
\end{abstract}

\section{Introduction}

During the last decade libraries were faced with budgetary restrictions and shortfalls that forced many administrators to limit or reduce their expenditures. As the cost of technical and public services operations reached its highest point, libraries began to explore ways to control and reduce these costs. ${ }^{1}$

While libraries focused on streamlining their processes and workflows, they began to shift more resources to technology and the emerging cooperatives, thus making better use of automation systems, consortia, and networks. Many institutions now subscribe to multiple systems and are part of consortia arrangements that often seem to duplicate services. Perhaps the time is right for libraries to question whether all of these mechanisms of delivering and accessing information are still of value.

As the new century dawns two trends affecting the delivery of information are emerging. On the one hand, technological advances are taking libraries into new territories that are offering new solutions for information delivery. On the other hand, the bibliographic record that forms the foundation needed to make best use of the new technologies is becoming less complete and less useful. $^{2}$

The purpose of this paper is to introduce new models that might come to serve as alternative solutions to the existing systems of processing delivery of information. In the scenarios presented here, the authors will attempt to challenge basic assumptions about the usefulness of and need for OPAC systems, Web OPAC's, OCLC (as a major bibliographic utility), and consortia. The authors will then identify ways that libraries can leverage their resources and available technology to create cost-effective ways of delivering improved services. 
"The purpose of this paper is to introduce new models that might come to serve as alternative solutions to the existing systems of processing delivery of information."

\section{Literature Review}

The world of librarianship has fundamentally changed since the advent of the Internet. Recently, some reports and articles have been published about the future of libraries, the future of cataloging and ways to revitalize and enhance the catalog, and retooling the cataloging workforce. ${ }^{3}$ However, there is hardly any literature that specifically points to the possibility of radically reevaluating the entire technological infrastructure of the local and shared OPAC. New ideas emerging from the library community at this time look at ways of linking library catalogs and union catalogs, such as OCLC's WorldCat, to the Internet.

In his 1999 article "Building Earth's Largest Library: Driving into the Future," Steve Coffman presented a vision of the future library based on the Amazon.com business model for the library world. In his vision, he proposed that libraries cooperate to create a single catalog incorporating all library holdings. The need for local circulation, cataloging, and interlibrary loan systems would therefore be eliminated. With the cost and resource savings of the model, Coffman suggested that libraries enhance catalog records and focus collections to support their specific patron population. In addition, by applying this model, libraries would have the potential to "radically reduce the traditional costs of library operations, both by significantly reducing automation expenses, and by allowing libraries to restructure their physical collections to be more responsive to customer demand."

An initial critical reaction to Coffman's article pointed to some social and technological obstacles that would have to be resolved before his dream of building such a library could be possible. The primary concerns included the cost of implementation, actual cost savings presented by Coffman, and the ability of technology to perform certain tasks better than a human. ${ }^{5}$ Later, in 2000, Barbara Quint published an editorial entitled "With OCLC's New Strategy, Is the Earth's Largest Library in Sight?" in which she points to significant similarities between OCLC's strategies and ideas put forth by Coffman. OCLC has since implemented many of Coffman's ideas by opening WorldCat to major search engines, such as Google and Yahoo! ${ }^{6}$

Digitization of library collections and increasing full text access is making an impact on the user community. John Markoff and Edward Wyatt wrote an article in the New York Times on the agreement between Google and leading US research libraries, as well as Oxford University, to begin converting their holdings into digital format that would be freely searchable over the Internet. In their article, Markoff and Wyatt mentioned that this effort might be a "step on a long road toward the long-predicted global virtual library." The authors also included in their article a valuable quote from Michael A. Keller, Stanford University's head librarian, who stated, "Within two decades, most of the world's knowledge will be digitized and available; one hopes for free reading on the Internet, just as there is free reading in libraries today."

Thomas Frey, in his article "The Future of Libraries: Beginning the Great Transformation," presented an excellent view of the future of libraries from a user's perspective. He discussed ten key trends that are affecting the development of the next generation of libraries. In some of the trends, Frey emphasized that today's technology will be replaced by 
something new and that technology is constantly changing. He also emphasized that the demand for global information will continue to grow. His statement that "the Stage is being set for a new era of Global Systems" is becoming reality. ${ }^{8}$

In his talk "Life beyond MARC: The Case for Revolutionary Change in Library Systems and Service," Roy Tennant gave a description of a future environment in which "libraries must switch their focus and resources toward the more efficient use of technology in their processes" to remain relevant in the technological age. ${ }^{9}$

Sources cited above allow for some speculation concerning current thinking about the future of libraries. From the review of the literature the authors made an assumption that libraries and librarians have begun to think about options for the transformation of access to library information into the future. A gap still exists, however, in the discussion of how libraries will deliver their information to users.

\section{Current Mechanism for Delivering and Accessing Bibliographic Information}

In the history of delivering and accessing bibliographic information, libraries have used catalog cards as surrogate records. In the 1970s and 1980s, libraries began to automate their processing and created the online public access catalog (OPAC) from catalog cards. This was accomplished through massive retrospective conversion that transferred data from the card catalog format to a machine-readable format. The OPAC mechanism delivered the same bibliographic description of library holdings to users with more features and methods for users to access information. During the same period, the concept of shared bibliographic records was developed and libraries recognized the merit and cost-effective benefits of sharing records. This sharing of bibliographic information was made possible through the introduction of two major bibliographic utilities, OCLC (Online Computer Libraries Center) and RLIN (Research Libraries Information Network). With the impending merger of OCLC and RLIN, OCLC will be examined here as the only bibliographic utility throughout the scenarios. ${ }^{10}$

The idea behind creating bibliographic utilities was to generate a record for each library item once, then shares this record through bibliographic utilities with other member libraries. Member libraries could then use and attach their holdings to a record so that patrons would be able to locate that item in their respective libraries as illustrated in Fig. 1.

In this diagram, which is commonly used by most libraries, library staff will search their online catalog (OPAC) to find a record for the item being cataloged. If the record is found, staff will add the copy or the volume of the item. If the record is not found in the OPAC, staff will search OCLC's WorldCat. If the required record is located in the database, staff will update the holding and export the record into their OPAC. If the record that is found does not exactly match the item, the cataloger will then edit the record to match the item on hand and export the records into the OPAC. If the item on hand is a different edition from that described in the catalog record, the cataloger will derive a new record using the information from the earlier edition and export the record into the OPAC. In this case, the cataloger sometimes chooses to edit only for their local online catalog and not to make changes in the master record in the bibliographic utility. If the cataloger does not find a matching record, the cataloger will use the online work-form and key in the information following national and international standard (such as AACR2, MARC21, LCSH, LCC, and other standards). 


\section{Figure 1}

\section{Current Mechanism for Delivering and Accessing Bibliographic Information}

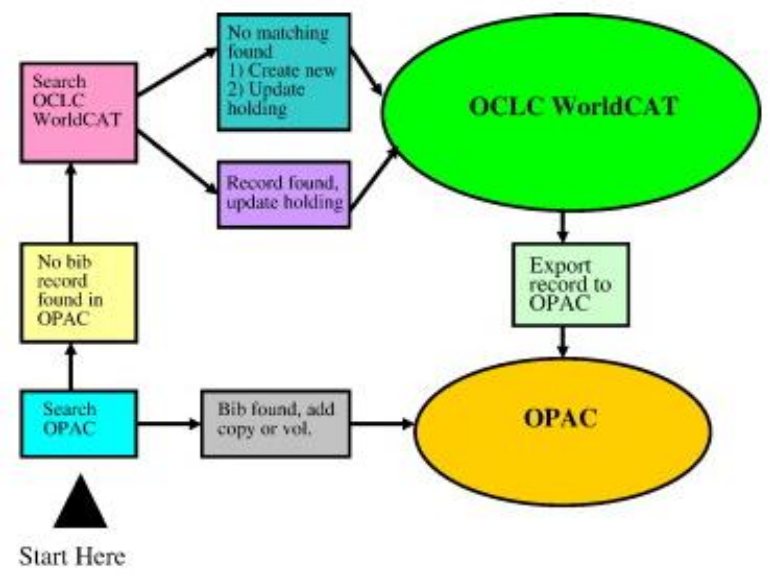

The record will then be "produced" into the bibliographic utility and then exported into the local library's OPAC.

In the late 1980s and early 1990s, some libraries began to organize local and regional consortia to further leverage their resources by taking advantage of the benefits offered by such cooperative arrangements. ${ }^{11}$ Some consortia provide support for major functions, such as providing a central catalog, ILL, and purchasing/licensing electronic information (i.e., OhioLINK), while other consortia provide a central catalog and purchasing/licensing, but not ILL (i.e., CARL). In this paper, the authors will take into consideration those consortia that provide a shared union catalog and borrowing services. The bibliographic record that each library created resides in the library's own OPAC system, the large database maintained by a bibliographic utility such as OCLC, and the regional network database managed by a local consortium.

The authors of this study raise the question of whether the current model that includes library OPAC's, bibliographic utilities, and the consortia offers the optimal solution for the library of the 21 st century. In other terms, can libraries streamline their mechanisms used to deliver and access information? Are libraries making the best use of today's technologies? Are libraries comfortable with these scattered services, assuming that users are provided with the best service?

To answer these questions, the authors will introduce several alternative scenarios with an aim to increase awareness of what new technologies can provide. Each of these scenarios is presented in an outline form and is not intended as a complete solution. Rather, it is a suggestion or a hypothesis that may lead to other solutions or ideas. In presenting these scenarios, the authors are making the following assumptions:

1. Search engines and the Internet are here to stay.

2. Search engines could be a new form of a bibliographic utility with more flexibility and accessibility.

3. Internet use will increase in the future. 


\section{Scenario 1: OPAC/Repository/Search Engines}

In this scenario the authors looked at the institutional repository as an interface that would provide the link between library's OPAC and Internet users (see Fig. 2). In doing so, we examined our own institutional repository and the way it operates. Although this repository is still in its infancy and does not contain a large number of resources deposited compared to our OPAC, all materials in the repository are indexed and accessible through Internet search engines.

Each record in the repository includes two parts: metadata, or information describing a digital resource, and the file(s) described by that metadata. In the repository, metadata are displayed with a link to a video file, audio file, image, application, data set, or the full text of the resource (if the resource is text-based). The metadata include descriptive data (author, title, associated date(s), use restrictions, an identifier, and any other data relating the content of the resource), technical data (file size, file type, date entered into database), and data required for preservation. The Dublin Core metadata standard is used to structure metadata in the repository.

At this time, metadata records and the full text of digital objects (if applicable) in the repository are accessible through Google, Yahoo!, and other Open Archives Initiative (OAI) harvesting Internet search engines. Software used to link the repository records to the Internet works very effectively and provides quick and easy access to stored digital files. The question that arises is whether the repository software can serve as effectively as an interface between a library's OPAC and Google and Yahoo!, thereby replacing the OCLC and consortium models.

\section{Figure 2}

\section{Senario 1: OPAC/Repository/Search Engines}

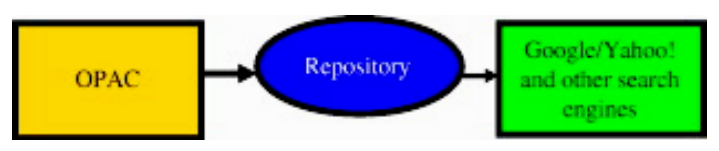

Can the repository software be used to access bibliographic data, that is, metadata, only? In other words can a repository record exist without a file attached- a non-traditional use of the software?

In order to experiment with this idea, a few bibliographic records were selected from the library OPAC system and input into the repository using the existing Dublin Core descriptive metadata structure. After allowing time for the records to be indexed by search engines, the records were searched by using author name and were retrieved in Google (for example, see Fig. 3). A link to the library's OPAC system guided the user to the holdings information about the items.

Searching author names only does not always produce highly ranked results. In fact, using popular names such as "Allan" and "Tucker" as search terms without quotes failed to return a repository hit in the first 10 pages. However, a search on another author and a keyword from the title produced a repository hit on the first Google results page (see Fig. 4). Fig. 5 shows the repository page that appears in the link from Google. Clicking on the title in that page will take users to bibliographic record data and a link to the library catalog record for holdings and other library services, as shown in Fig. 6. 


\section{How This Scenario Works}

1) At first, information from the MARC fields needs to be assigned to Dublin Core fields.

The MARC Content Designation Utility portion of the Z-Interop Project at the University of North Texas has taken steps toward identifying the most frequently used MARC fields by catalogers and the retrieval efficiency of those fields. ${ }^{12}$ This and similar projects will help libraries choose what MARC fields to translate to repository records.

If desired, all of the information in the MARC record can be used in the repository record. Figs. 6 and 7 show bibliographic data for the same masters thesis in both, the repository and the Web OPAC.

Format information (microfiche, etc.), OCLC number or holdings information was not included. However, authoritative name and subject headings were retained.

2) Second, records must be input into the repository. The input process can be manual or automated.

Manual input: Bibliographic records have to be input one at a time. Figs. 8 and 9 show our repository's first two manual submission screens. After entering the metadata, a dummy file must be uploaded to complete the creation of a record in the repository. After the repository record has been created, the dummy file must be manually removed, leaving only the bibliographic data.

Batch input: Existing open source and proprietary tools can be used to repurpose MARC metadata into a more universal data format $-\mathrm{XML}$, which is the format needed for import and export from the repository.

Figure 3

First Google Results Page Based on an Author Search

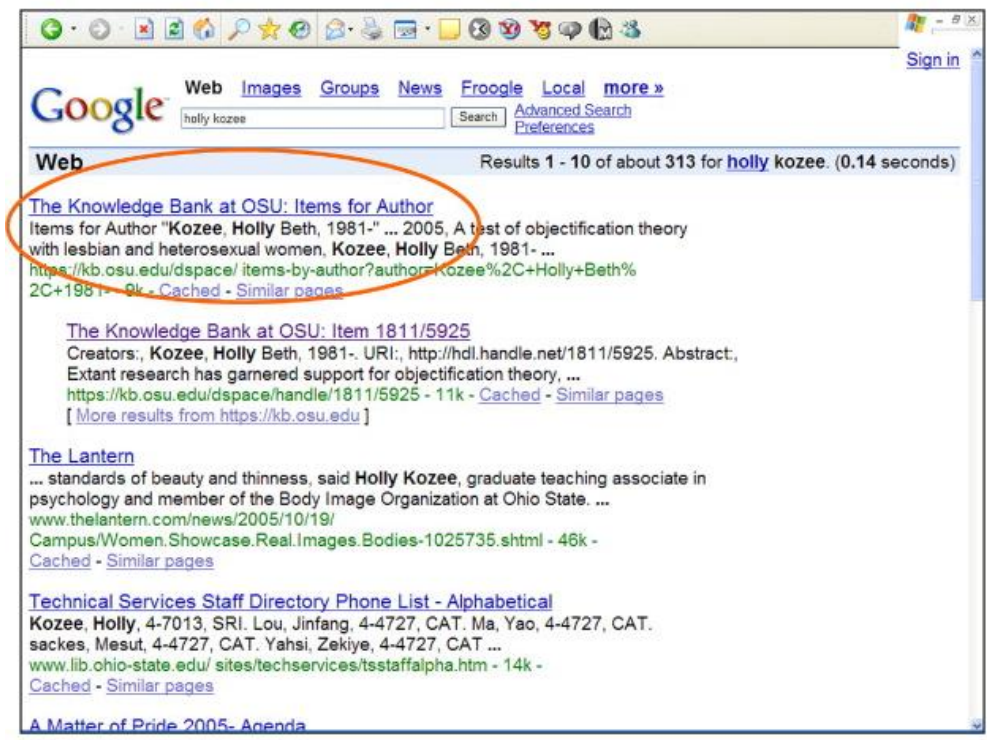




\section{Figure 4 \\ First Google Results Page for Search Including Author Name and Keyword from Title (Query: Allan tucker Attrition)}

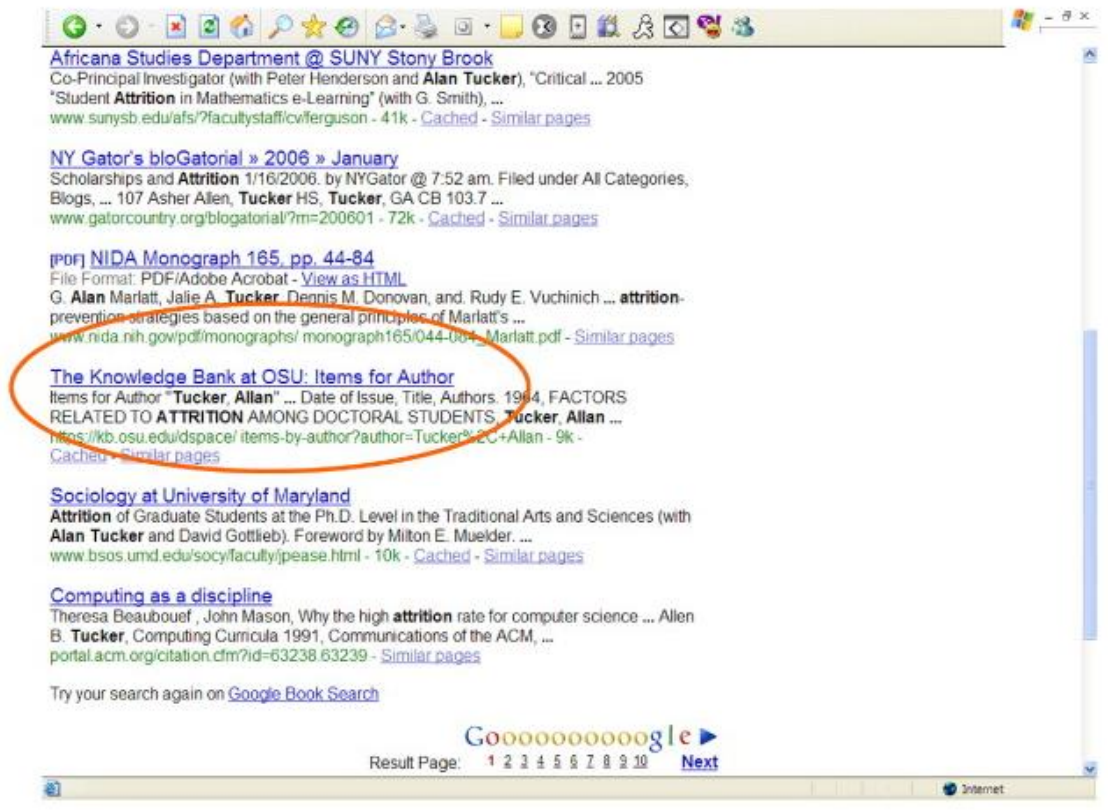

One example of such software is MARCedit. ${ }^{3}$ By using these tools, records can be imported into the repository in automatic batches and dummy files need not be attached and removed in the process.

3) Third, libraries will maintain their current local OPAC systems to manage acquisition, ILL, circulation, and the collection maintenance functions of the OPACs.

\section{Advantages}

- Libraries will repurpose MARC format metadata into XML format, an open format. The XML format is becoming ubiquitous outside the library community. XML tools are increasingly available. Library data can be easily integrated into users' infosphere. Bibliographic data can also be easily decoded both within and outside of the library community.

- Libraries will increase access to the "hidden collections" (e.g., ERIC collections, archival and special collections, and thousands of "short records" or k-level records in OCLC or our catalogs). If libraries do not wish to have some materials available to users, they may still suppress these records in their local OPAC. In this manner suppressed records will not be exported to the repository.

- Bibliographic records can be easily edited in the repository software and can be customized or expanded to meet users' needs. 
- Implementation of this scenario will eliminate the need to store bibliographic records in bibliographic utilities (OCLC/ RLIN). This will eliminate the fees that libraries pay for record retrieval and the cost of membership fees.

- Library records will go directly from the library repository to the search engines.

\section{Disadvantages}

- Libraries may need the same or higher levels of IT support to integrate open source tools into the traditional cataloging workflow.

- Increased IT support for the use, configuration, and customization of open source repository tools may be needed. To support this scenario, programming of the repository software to expand intended uses and purposes of that software is needed. For example, allowing a repository record to exist without an attached file.

Figure 5

Following the Link from Google into our Repository

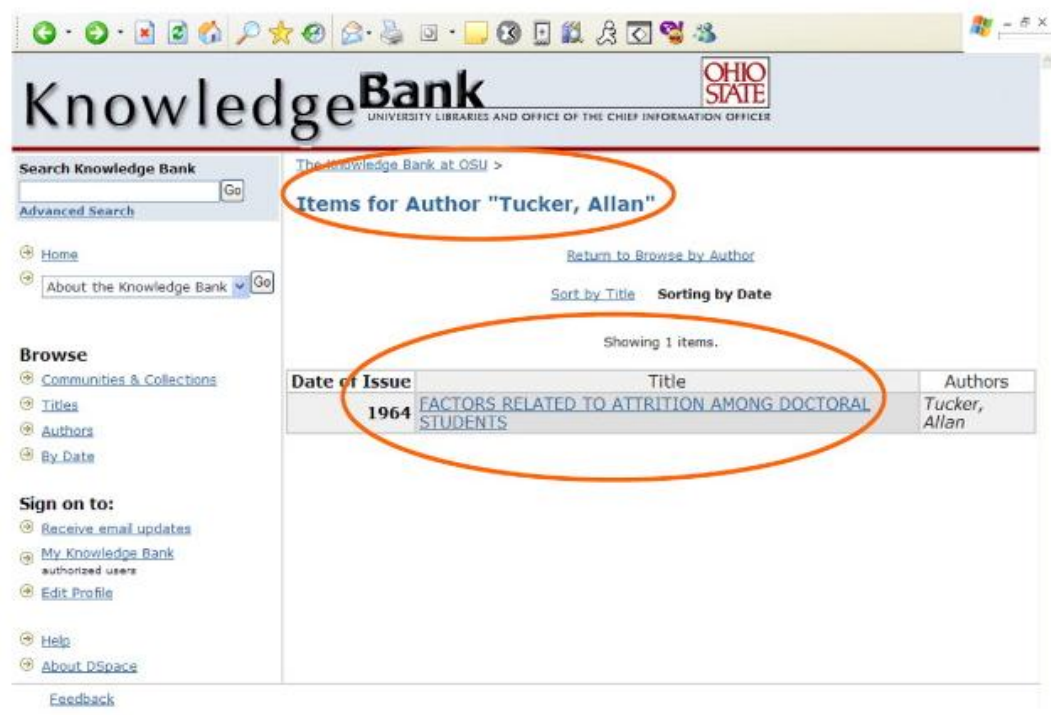

- New policies and standards are needed to determine how to represent complex bibliographic relationships expressed in MARC records (example-series, successive titles, etc.) in a less complex metadata structure.

- If each individual library inputs their bibliographic records into the repository that is searched by the Internet, then hundreds of records for the same resource will appear through an Internet search. Search engine designers or libraries will have to find a way to eliminate this duplication.

- Libraries will have to develop a new way to conduct ILL transactions without OCLC. 
- Enormous task of loading hundreds of thousands of rich MARC catalog records into the repository.

\section{Scenario 2: Consortia/OCLC WorldCat/Search Engines}

This model proposes the elimination of the local OPAC and creation of a consortiumlevel OPAC among several libraries (see Fig. 10). The consortium will serve as a MEGA OPAC for those member libraries. The consortium will contribute records to OCLC's WorldCat and these records will then be made available to Internet users through Open WorldCat.

\section{How This Scenario Works}

1) Libraries will use workstations to access and input records into the consortium database. The consortium will contribute records to OCLC and Open WorldCat.

2) Libraries will not have an Integrated Library System (ILS) or an individual catalog, but will submit all their catalog records to the consortium database. The records will then be migrated to the OCLC WorldCat database for indexing and made available through the Internet utilities such as Google and Yahoo!. The consortium database will be used to identify local holdings, execute ILL transactions, and circulate materials. For example:

a) Users will search Google, Google Scholar, or Yahoo! as usual. Users will enter their search as follows: "Find in a Library: Harry Potter and the Goblet of Fire."

b) Users will select the item they want from Google, Google Scholar, or Yahoo! list (see Fig. 11).

c) Users will enter the zip code to locate the item in a nearby library. In this example the "Ohio State University" (OSU)—-shows that the work is in OSU Libraries.

d) When the user clicks on the "Ohio State University" the link will take the user to the consortium catalog to get to ILL, etc. In this case, users will be taken to the OhioLINK Web catalog (Fig. 12), instead of OSU's local webPAC.

3) Consortia will have memberships to OCLC, so that non-subscribing libraries will have access to OCLC's WorldCat and functions such as ILL linking. 


\section{Figure 6}

Masters Thesis Bibliographic Record in Ohio State University Repository

\begin{tabular}{|c|c|c|c|}
\hline$\theta \cdot \theta \cdot x$ है \& & (8) $8 \cdot \beta$. & 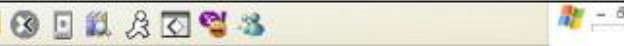 & \\
\hline $\begin{array}{l}\text { Search Knowledge Bank } \\
\text { Advansed Suerch }\end{array}$ & $\begin{array}{l}\text { Ihe Knowedge Briok at os: } \\
\text { Z. Sample Community II > } \\
\text { Test collestion 3 > }\end{array}$ & & \\
\hline (5) Home & Please & $\begin{array}{l}\text { e use this identifier to cite or link to this item: } \\
\text { http://hdl. handle.net/1811/5925 }\end{array}$ & \\
\hline 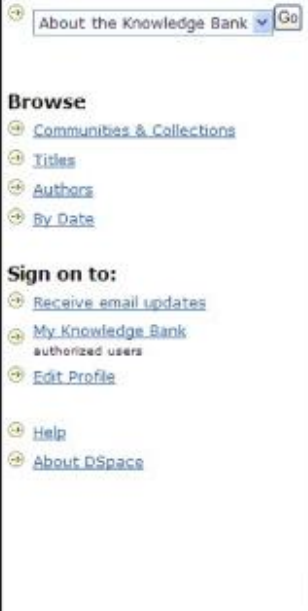 & $\begin{array}{r}\text { Title: } \\
\text { Creators: } \\
\text { Contributors: } \\
\text { Keywords: } \\
\text { Issue Date: } \\
\text { Publisher: } \\
\text { Series/Report No: } \\
\text { Abstract: }\end{array}$ & $\begin{array}{l}\text { A test of objectification theory with lesbian and heterosexual } \\
\text { women } \\
\text { Kozee, Holly Beth, 1981- } \\
\text { Tylka, Tracy L } \\
\text { Body image in women } \\
\text { Lesbian college students } \\
2005 \\
\text { The Ohio State University } \\
\text { Thesis (M.S.)--Ohio State University, } 2005 \\
\text { Ohio State University. Dept. of Psychology } \\
\text { Extant research has garnered support for objectification } \\
\text { theory, a model of women's body image that indirectly links } \\
\text { sexual objectification to eating disorder symptomatology. The } \\
\text { purpose of the study was to investigate the applicability of } \\
\text { objectification theory to lesblan women. A sample of } 181 \\
\text { lesblan women and } 196 \text { heterosexual women were recruited } \\
\text { through college campuses. Measures for sexual objectification, } \\
\text { self-objectification, body shame, appearance anxiety, } \\
\text { interoceptive awareness and disordered eating were } \\
\text { administered. The results provided evidence that the present } \\
\text { model of objectification theory does not hold for lesbian } \\
\text { women } \\
\text { htto://hdli.handle, net/1811/5925 } \\
\text { Call No: THE:PSY2005MAK694 } \\
\text { Test collection } 3\end{array}$ & \\
\hline & & $\begin{array}{l}\text { Files in This Item: } \\
\text { There are no files associated with this item. }\end{array}$ & \\
\hline & & B. internet & \\
\hline
\end{tabular}

\section{Advantages}

- Libraries will be able to centralize their operations and reduce redundancies.

- Libraries will be able to eliminate their local OPAC systems and manage their catalogs through consortia.

- Circulation, inventory control, and ILL would need to be handled at the consortium level.

- Redundant costs for maintaining individual local OPACs and processing an item several times by multiple libraries will be eliminated.

- Increased standardization and cooperation among libraries will be encouraged.

- Holdings information stored in regional consortium databases can help libraries in their selection and acquisition process by allowing them to eliminate redundancy that results from buying the same items for many libraries in the same region. This is likely to foster cooperation and reduce acquisition costs.

- Libraries not currently using online systems may move to automated systems. For example, school libraries that cannot afford to have their own OPAC will be able to contribute holdings to the consortium through workstations linked solely to the consortium.

- IT support for OPAC maintenance and functions will be centralized at the consortium level. 
Other IT functions, such as public workstations, will be maintained by individual libraries.

\section{Disadvantages}

- Consortia will assume a larger role in regional cooperation and coordination. Consortia will need to develop and employ methods to enable member libraries to manage their local collections through a central catalog (ILL, circulation, etc.). Authority of the consortium will not include oversight of individual library budgets.

- Libraries might encounter difficulties in establishing cooperative models for regional collection development policies.

- The potential for difficulties in coordinating acquisition activities among the libraries exists.

- Coordinating communication and activities among member libraries could be difficult.

- Libraries will have to give up local OPACs, which may be seen as losing a measure of control.

- Some non-OCLC libraries may have to become members to take advantage of ILL and other functionalities WorldCat offers.

Figure 7

Masters Thesis Bibliographic Record in Ohio State University Web OPAC

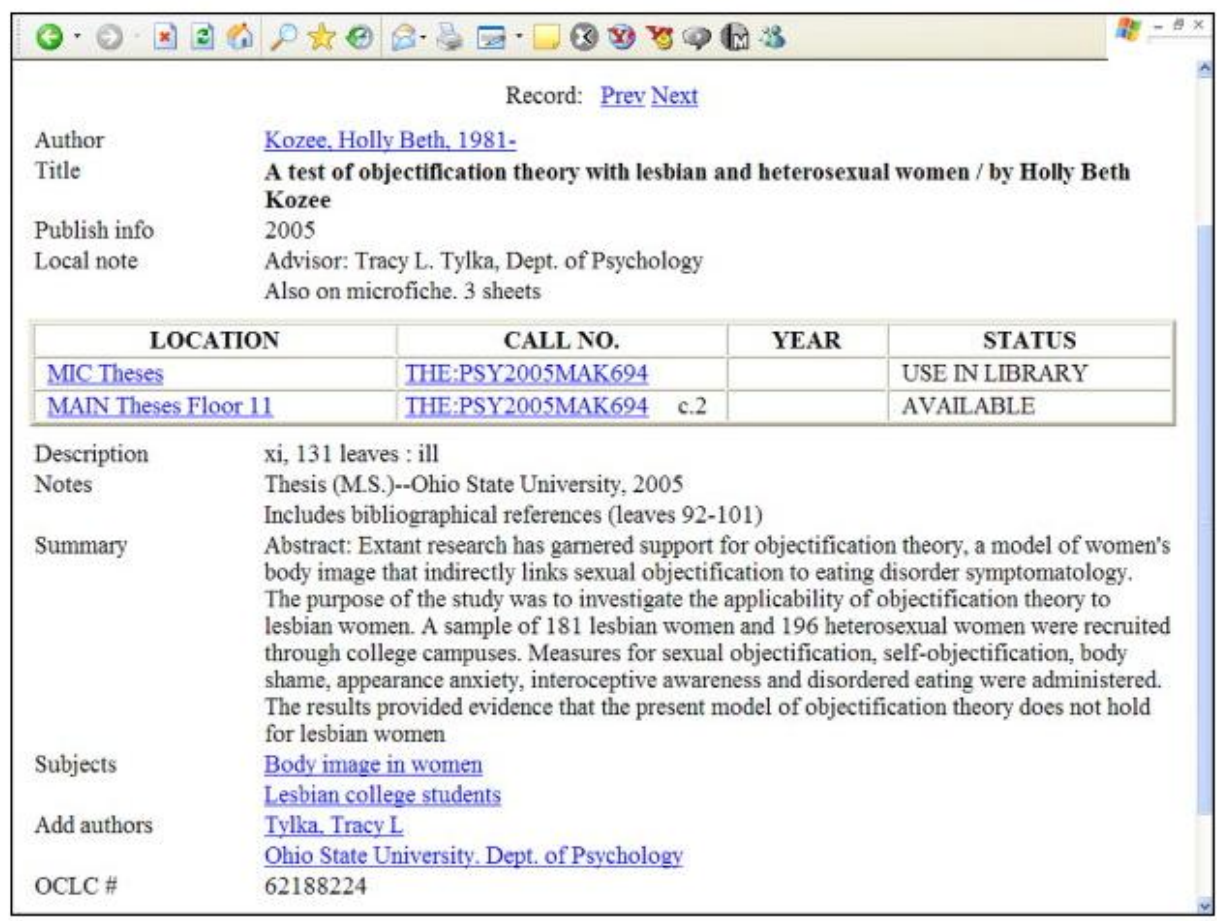




\section{Scenario 3: OCLC WorldCat/Search Engines}

In this scenario, libraries no longer maintain their catalogs (see Fig. 13). Instead, each library submits their cataloging records electronically to OCLC via workstations linked solely to OCLC. WorldCat becomes a de facto catalog for each library. This scenario also utilizes an existing OCLC tool in development, OCLC Resource Sharing, in an effort to leverage available resources. Libraries retain the circulating/lending/ borrowing functionality locally through the acquisitions and inventory modules of current ILS systems.

In this scenario, libraries will need to do the following:

- Link workstations to OCLC (e.g., using Connexion).

- Search OCLC as usual to find a copy and attach holdings to existing records.

- Create and input a new record into OCLC through a template, if a record for an item does not already exist in OCLC.

\section{How This Scenario Works}

1) OCLC will make library bibliographic records available to Google, Yahoo!, and other Internet search engines.

2) Users will search the WorldCat database through the Internet search engines or OCLC's FirstSearch to retrieve a list of records.

3) Users will select the record they want and be prompted to another screen with a brief record, holdings information, and a "request this item" option.

4) Users can click on the "holdings information" field to determine which library owns the item. Then they may select the "request this item" option.

5) Initiating the request will prompt the user to OCLC WorldCat Resource Sharing.

6) The Resource Sharing process will allow users to select the library from which they want to borrow materials as illustrated in Fig. 14.

7) For in-library users, terminals linked to WorldCat or to any Internet search engine will be the starting point. If users find a material housed in their local library, they have the option to retrieve and borrow the items in person.

8) Libraries will need to retain some sort of circulation and ILL modules that will interface with OCLC Resource Sharing.

9) Libraries will have to keep some circulation tools for on site users. In addition, libraries will 
need to maintain control over ILL for borrowing. Perhaps the circulation and acquisitions modules of current ILS systems will suffice.

Figure 8

Manual Submission Screen - First Page of Descriptive Information

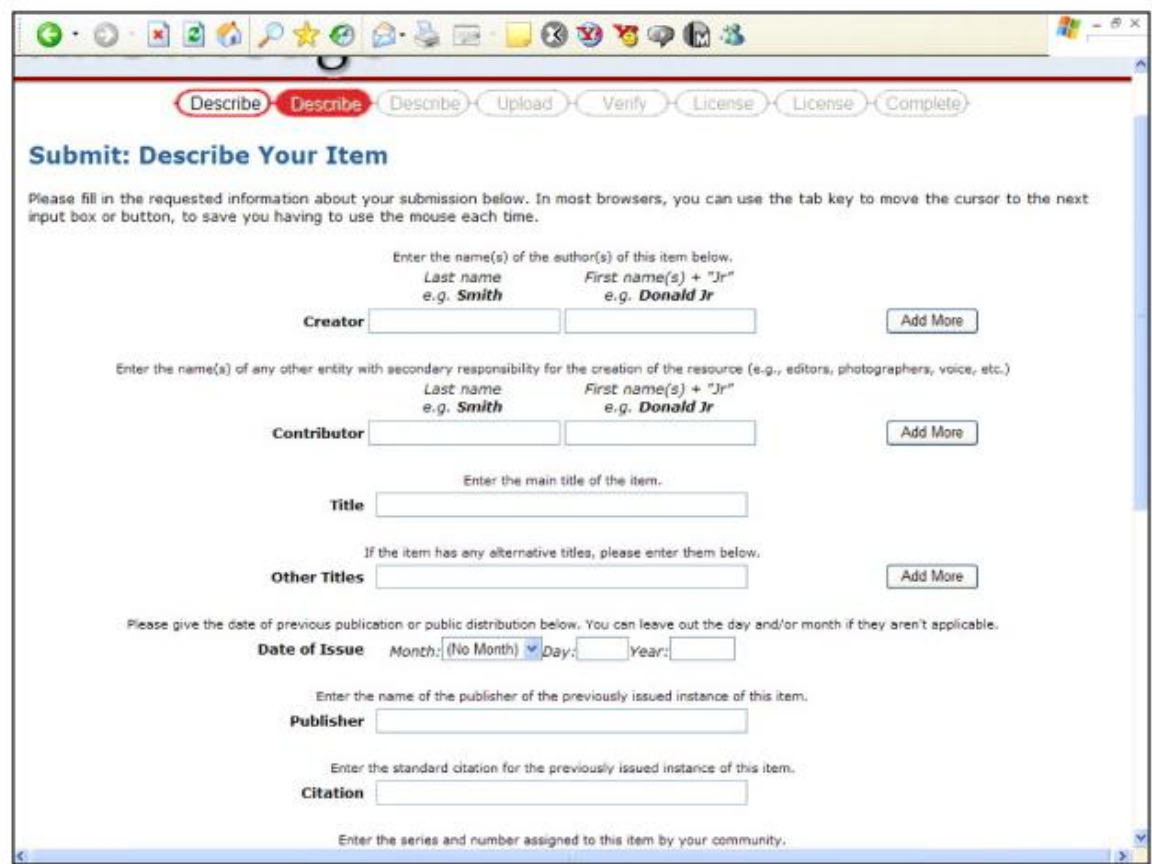

\section{Advantages}

- This scenario eliminates some of the costs associated with purchasing full ILS systems and maintaining library catalogs internally. This may also eliminate the cost of consortia membership, if the library participates in any consortia. OCLC will assume an even greater role in cooperative cataloging, and will save libraries time and perhaps cost in managing their collections.

- Without the OPAC, libraries will be forced to add all of their records to the OCLC database. Short records will be submitted to WorldCat to be shared with other users. Other libraries will be able to upgrade these if they want to have full bibliographic records. This will enable all types of libraries to participate in a truly cooperative cataloging venture.

- Smaller libraries that do not have OPACs will be encouraged to contribute records directly to OCLC via the Internet.

- The need to download records into local OPACs will be eliminated.

- Internet users will promptly access libraries' materials through Internet search engines.

- Libraries' dependency on ILS vendors will be radically reduced. This is an important issue 
because libraries have spent tremendous amounts of time and money purchasing, upgrading, and maintaining their ILS systems. ILS vendors would have to adapt, and supply stand-alone circulation, acquisition, and ILL modules. In addition, ILS vendors can help integrate libraries' collections with the major search engines through XML exporting and conversion capabilities.

- Library staff will be able to devote more time to the actual enhancement of bibliographic records.

- IT maintenance and support needs might be reduced on the local library level. For example, the need for communication with the ILS vendors for system enhancements and for implementing a new module and staff training will be greatly reduced.

- Libraries will have the capability to add acquisition order records into OCLC. If OCLC will develop such a module, this will help determine how many copies of an item are ordered and help make the OCLC database an innovative tool for collection development. A selector could check local and regional holdings of titles to make informed collection management decisions.

- Libraries will retain control over their own budgets.

- Libraries will follow the same standards for creating catalog records.

- This scenario is a safe option to consider because OCLC is an established service provider that has been working with libraries for over thirty years.

- This scenario presents libraries with an opportunity to rethink the ownership vs. access issue. The advantage is that there would be less duplication of owned copies.

Figure 9

Manual Submission Screen - Second Page of Descriptive Information

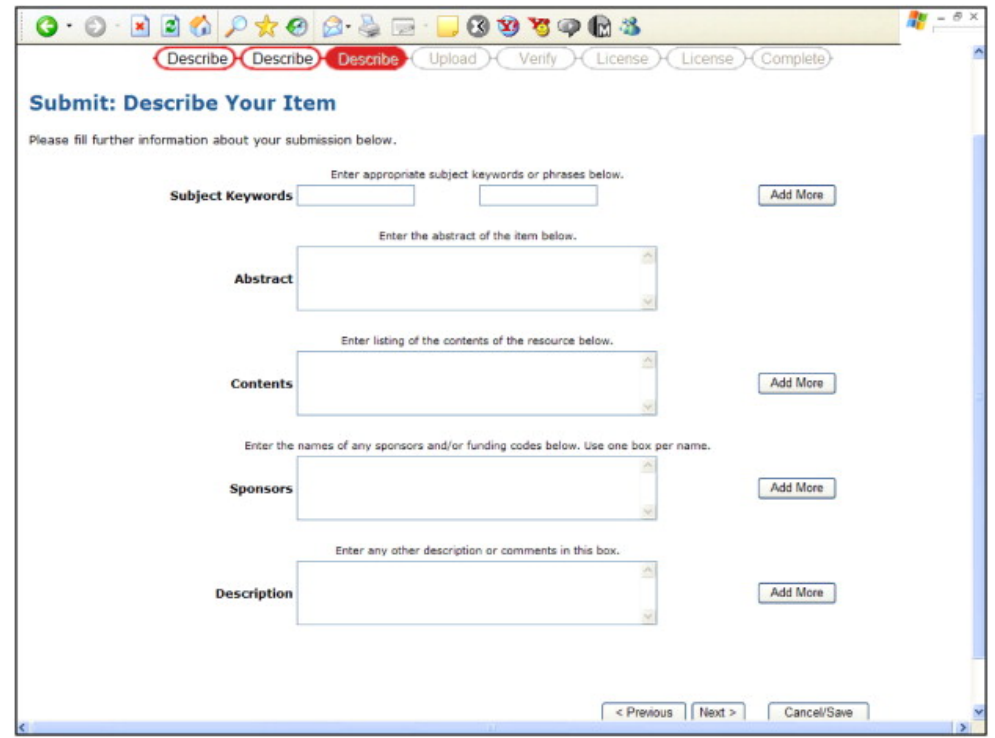




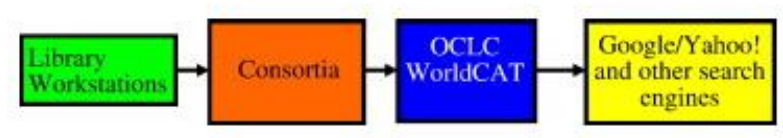

\section{Disadvantages}

- Libraries will have to maintain some functions, such as ILL, acquisitions, and circulation on the local level or OCLC has to take on the entire ILS functionality. Currently, all of the ILS library's subsystems are linked to an institution's bibliographic record.

- OCLC has to redesign the interface that displays item-level information, holdings information, and request item capabilities. For example, OCLC will not only indicate which libraries own a particular item, but also provide specific information about the item in a specific library (e.g., copy number, volume holdings, circulation status, location within the individual institution, check-in records, etc.). ILS vendors provide this information and customization for individual libraries. Would OCLC be willing to take on this role?

- If the OCLC network goes down, the entire library network goes down unless software/hardware is sophisticated enough to handle the backup of the database.

- Creating and maintaining a complex database or database network that works smoothly, consistently, and flexibly will be a challenge.

Figure 11

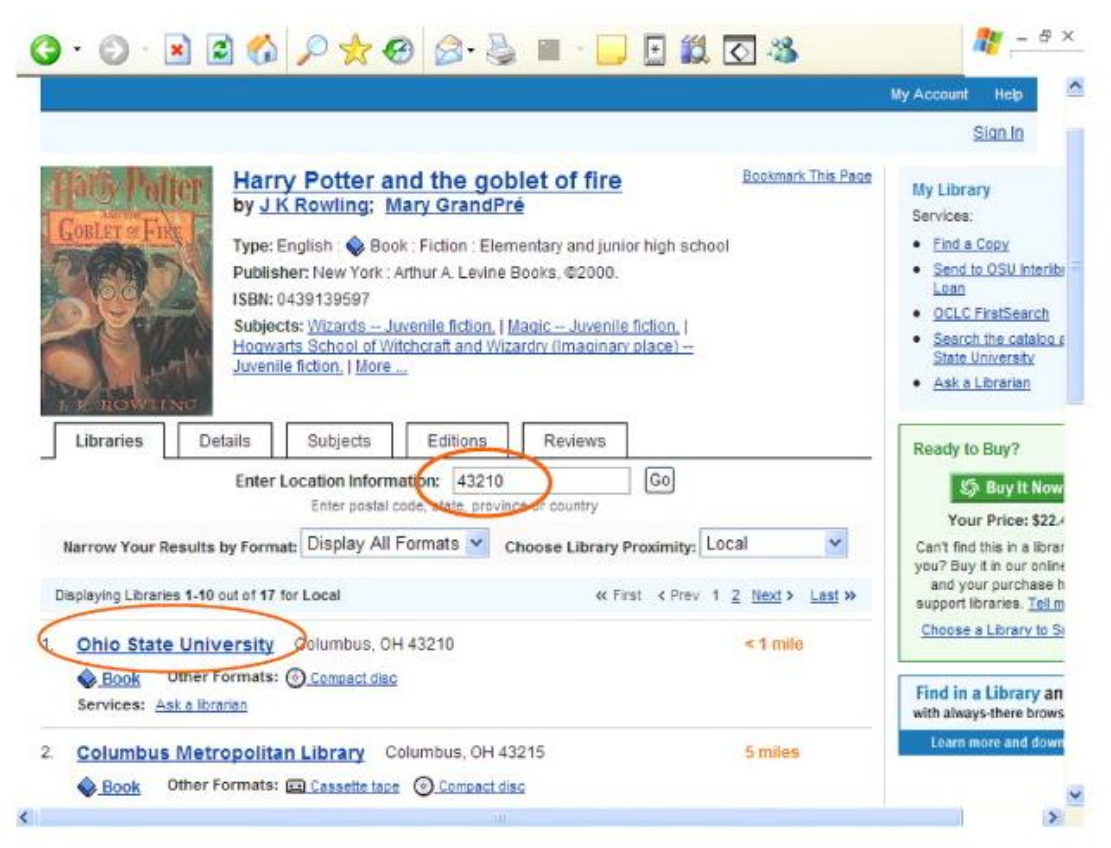

- More bureaucracy within OCLC will be needed to handle increased staffing needs required to 
communicate and coordinate with individual libraries and manage the database.

- Libraries will cut costs of maintaining their own OPAC, but there may be a significant increase in the cost of membership to OCLC and for handling information through OCLC.

\section{Scenario 4: Local OPAC/Search Engines}

Search engines can be a virtual catalog and replace the bibliographic utilities (see Fig. 15). All intermediate steps including consortia and OCLC will be bypassed.

\section{How This Scenario Works}

1) Libraries will catalog in their own OPACs and maintain their databases for all normal library functions.

2) These databases will be directly searchable by search engines.

3) Library cataloging staff will search the Internet to find an existing record for an item.

4) The record will be downloaded by the owner library through the Internet (this functionality already exists in online banking).

5) If no record is found through the search, libraries will catalog the item in their own system. The record will subsequently be available on the Internet for other libraries to use.

\section{Advantages}

- Libraries will have access to international bibliographic records.

- Libraries do not need specific software designed to harvest bibliographic information only (i.e., OCLC's Connexion).

- The Internet would provide true international tools for collection development and selection.

- Users will have quicker access to bibliographic holdings of libraries from anywhere in the world.

- Internet users will have true visibility of libraries' holdings.

- Many of the costs associated with contributing records to bibliographic utilities and subscriptions will be eliminated. For example, now libraries have to subscribe to OCLC's WorldCat and pay fees for any transaction, in a complicated cost structure. Libraries are paying to get their own records into the Open WorldCat and, by extension, into Google.

- Cost savings may occur due to changes or elimination of consortium member fees. 
Figure 12

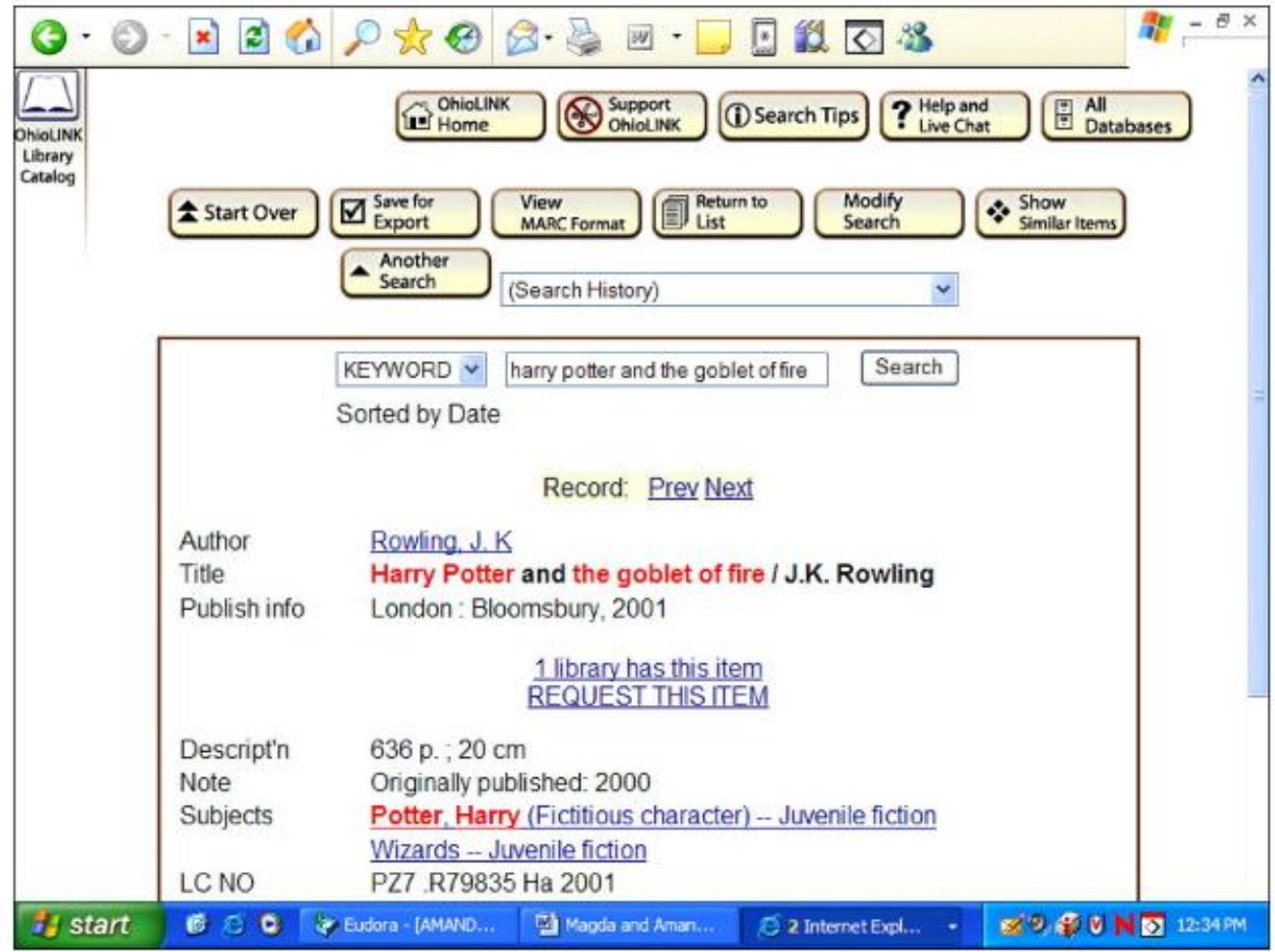

\section{Disadvantages}

- Search engines will display many records for the same item held at different libraries. A remedy might be a programming solution that will eliminate duplication and allow for holdings display.

- The capability for search engines to harvest library records directly from the OPACs will need to be implemented.

- A central database such as OCLC's WorldCat is no longer available.

- Libraries will have to establish mechanisms to share records among themselves.

- All participating libraries will need to reinforce their commitment to use standard protocols and cataloging rules.

- ILS vendors will need to work together to establish standard practices and displays.

- The danger that search engines may collapse, go bankrupt, or no longer want to support this service in the future exists. 
Figure 13

Senario 3: OCLC WorldCat/Search Engines

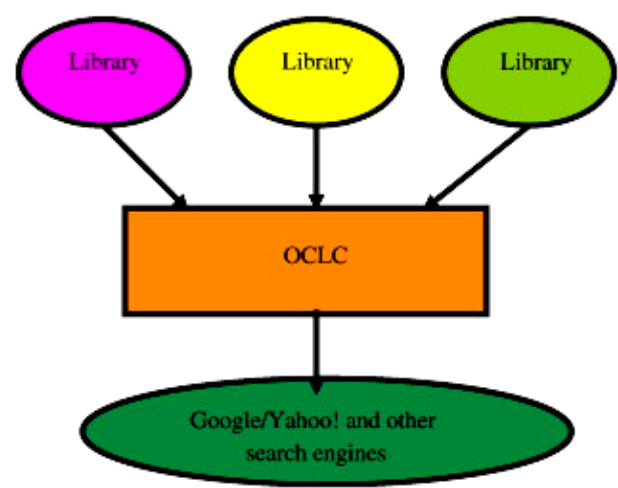

Figure 14

Resource Sharing Process

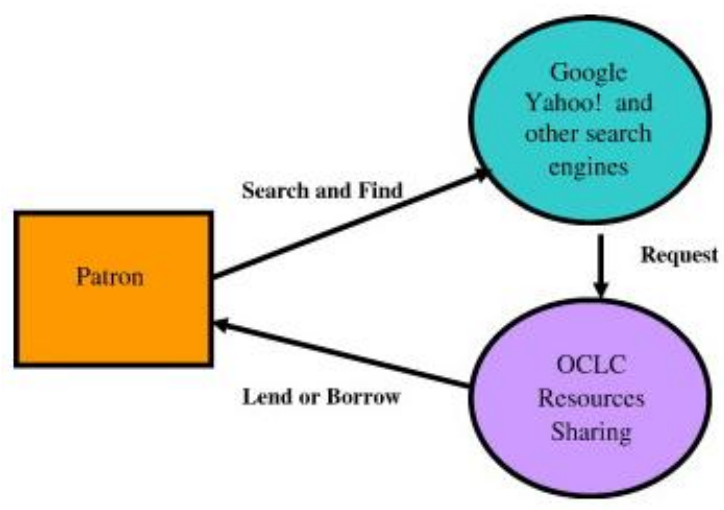

Figure 15

Senario 4: OPACs/Search Engines

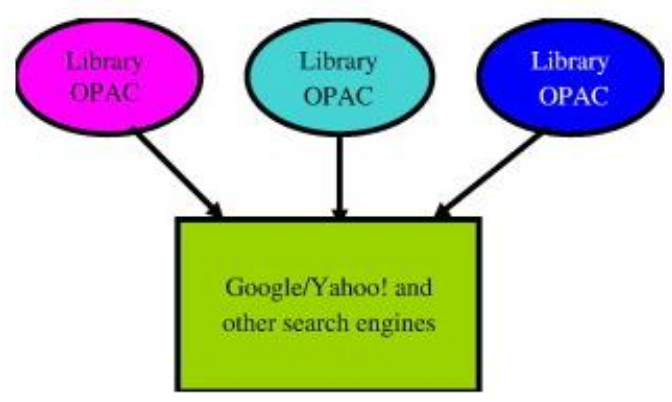




\section{Scenario 5: OPACs/OCLC's WorldCat/Search Engines for Printed Materials Repository/Search Engines for Digital Materials}

In this scenario, libraries will use OPACs to catalog print materials, as they currently do, and use repositories to catalog digital resources as it is illustrated in Fig. 16.

Many libraries have been establishing their own repositories to serve their campuses. These repositories can accommodate any digital resources. In examining other library repositories, including the repository at the authors' institution, the authors found that they can contain digital theses and dissertations, articles, images, transcripts, monographs, data sets, HTML files, etc. All of these materials are accessible and indexed via the Web. Libraries are making substantial additions to repositories. The question that arises is why do libraries have to go through a long processing cycle that includes cataloging digital resources in the MARC format, adding them to their OPAC, adding them to OCLC, and making them available to Internet search engines.

\section{How This Scenario Works}

1) Libraries will catalog print materials as in the current scenario.

2) Libraries will deposit digital resources into institutional repositories which are indexed and accessible to users via the Internet.

\section{Advantages}

- Local OPACs focused on describing printed materials will be maintained. These records can be made available to the Internet search engines through Open WorldCat.

- The redundancy of having records for a single resource in multiple places will be eliminated.

- Using institutional repositories provides the opportunity for a fresh start to use a different technology to describe and access digital resources, before libraries continue to change, adapt, and modify their practices, codes, and standards to accommodate digital resources further.

- The institutional repository format (as well as databases and other digital library formats) could be viewed as a potential OPAC for digital resources.

- In examining some of the repositories' materials, including the repository at the authors' institution, we found that the majority of the digital materials are already indexed and displayed in the major search engines.

- The cost of cataloging and adding digital materials to the OPAC may be saved.

- This scenario is not as radical a change for libraries as the other scenarios presented.

- Users may find resources more efficiently because they do not have to go through an 
intermediary to access digital resources, which are quickly indexed in search engines.

- Both sets of records from the repository and the OPAC are indexed by the Internet search engines.

\section{Disadvantages}

- This is not a large obstacle, but the process to access licensed digital resources is already established with the OPACs and it might have to be translated to work in the repository environment. Also electronic resource management systems have functions for payment, licensing information, use statistics, URL management, etc., built in that will need to be addressed.

Figure 16

Senario 5: OPACs/OCLC WorldCat/Search Engines for Printed Materials

Repository/Search Engines for Digital Materials

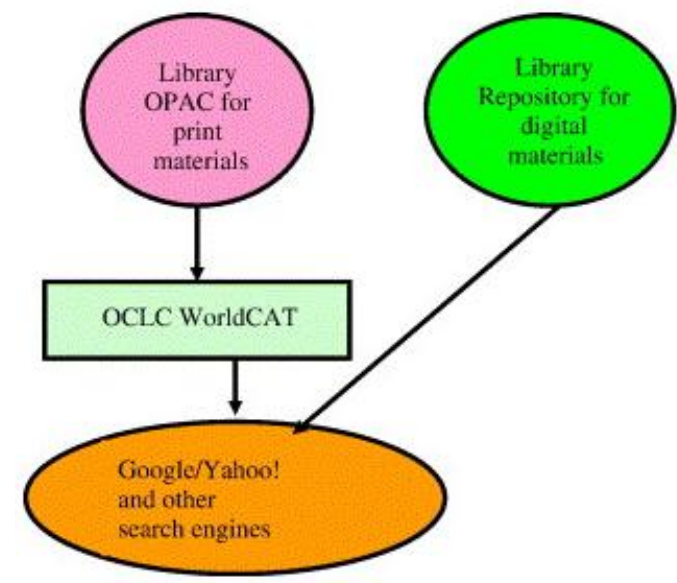

- Libraries will have to maintain an OPAC and a repository. Some libraries do this already.

- So far, libraries are using DSpace for storing their digital materials. This software might be too limited to handle massive digitization projects.

\section{Conclusion}

By presenting a number of options for consideration, the authors of this paper highlight potential solutions to some important issues facing libraries. Options presented here are intended to initiate a debate in the library community about the mechanisms that libraries currently use to share bibliographic records in order to facilitate access to information. These options do not exhaust all possibilities that might be available and it is our hope that more ideas and potential scenarios will be generated in response to the thesis of this project.

It is our belief that library administrators, who until now have focused most of their 
attention on streamlining internal operations of their technical and public services, ought to include in their considerations those mechanisms and tools that connect library collections to their users.

Thirty odd years ago libraries took a huge leap into the future by beginning to automate their catalogs and other operations. Technology once again presents libraries with an opportunity to take the next leap. This time, the leap will take us fully into the Internet world, where most of our users already reside. To begin this process we need to analyze some basic assumptions about the legacy systems that have served us so well for so long, and to seek new solutions.

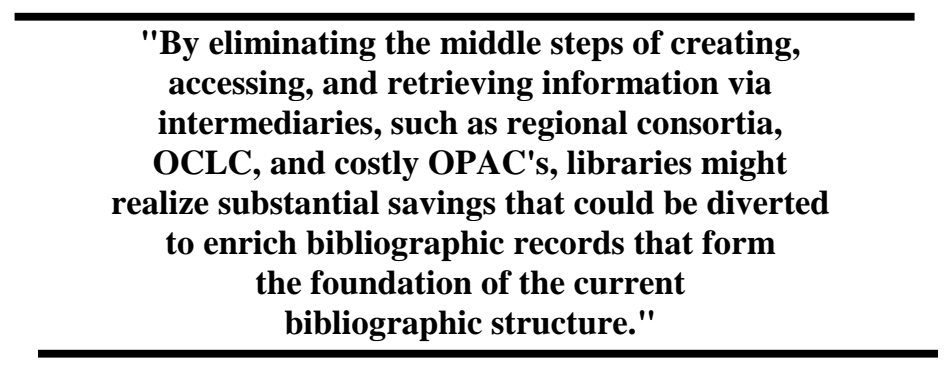

We take our cue from the user community itself. There is less interest in retrieving bibliographic records with pointers to a building and a shelf where the desired information is housed. Instead, today's users want and prefer easy on-line access to full text information. What makes this scenario exciting is that libraries are in a good position to provide full text access to some materials that exist in digital formats. Libraries can also satisfy the need for prompt delivery of materials where full text is unavailable. This can be achieved by offering easy-tounderstand and access-enhanced bibliographic information linked to a delivery system that offers service directly to the user.

By eliminating the middle steps of creating, accessing, and retrieving information via intermediaries, such as regional consortia, OCLC, and costly OPAC's, libraries might realize substantial savings that could be diverted to enrich bibliographic records that form the foundation of the current bibliographic structure. One of the key questions is whether librarians can envision a future without the OPACs, the consortia, and bibliographic utilities, and embrace the major Internet search engines as the "Earth's Largest Library".

Acknowledgment: The authors wish to thank George Klim for reading this article and making valuable comments.

\section{Notes and References}

1. Innovative Redesign and Reorganization of Library Technical Services Paths for the Future and Case Studies," edited by Bradford Lee Eden (Libraries Unlimited Westport, 2004), p. 480; Kathleen L. Wells, "Hard Times in Technical Services: How Do Academic Libraries Manages? A Survey," Technical Services Quarterly 21 (4) (2004): 17-30, Available at: http://www.haworthpress. com.proxy.lib.ohio-state.edu/store/EText/View_EText.asp?sid=5SA5DBCMR6F19J87PUWS885REB055TB0\&a=4\&s=J12 $4 \& \mathrm{v}=21 \& \mathrm{i}^{\wedge} \& \mathrm{fn}=\mathrm{J} 124 \mathrm{v} 21 \mathrm{n} 04 \% 255 \mathrm{F0} 2$ (Accessed June 8, 2006); Karen Calhoun, "Technology, Productivity and Change in Library Technical Services," Library Collections, Acquisitions, and Technical Services 27 (3) (Autumn 2003): 281-9, Available at: http:// journals.ohiolink.edu.proxy.lib.ohio-state.edu/local-cgi/send-pdf/ 060502133946493345.pdf 
2. "Levels of cataloguing treatment applied by the National Library of Canada" (Revised August 2003), Available at: http://www. collectionscanada.ca/6/17/sl 7-201-e.html (Accessed June 8, 2006); "LC to implement Core Level Cataloging," Available at: http://www. loc.gov/catdir/cpso/corelev.html (Accessed June 8, 2006); "Definition of Cataloging Levels," Available at: http://165.112.6.70/tsd/_cataloging/DefCatLev.html (Accessed June 8, 2006).

3. "The Changing Nature of the Catalog and its Integration with Other Discovery Tools: Final Report" prepared for the Library of Congress by Karen Calhoun, Cornell University Library (March 2006): 52, Available at: http://www.loc.gov/catdir/calhounreport-final.pdf (Accessed June 8, 2006); Deanna B. Marcum, "Future of Cataloging" Library Resources and Technical Services 50 (1) (January 2006): 5-9, Available at: http://wilsontxt.hwwilson.com/pdffull/01 866/zg4ee/8sb.pdf (Accessed June 8, 2006); "Rethinking How We Provide Bibliographic Services for the University of California: Final Report" (December 2005): 80, Available at: http://libraries.universityofca-lifornia. edu/sopag/BSTF/Final.pdf (Accessed June 8, 2006); "A White Paper on the Future of Cataloging at Indiana University" (January 2006), Available at: http://www.iub.edu/ libtserv/pub/ Future_of_Cataloging_White_Paper.doc (Accessed June 8, 2006); North Carolina State Libraries, "NCSU Libraries Unveils Revolutionary, Endeca-Powered Online Catalog," News Release (January 2006), Available at: http://www.ncsu.edu/news/press_releases/ 06_01 /007.htm (Accessed June 8, 2006).

4. Steve Coffman, "Building Earth's Largest Library: Driving into the Future," Searcher 7 (3) (March 1999), pp. 34, 12.

5. Mark E. Napier and Kathleen A. Smith, "Earths Largest Library-Panacea or Anathema? A Socio-Technical Analysis: A detailed critique of Coffman's proposal" (May 2000), Available at: http:// rkcsi.indiana.edu/archive/CSI/WP/wp00-02B.html (Accessed June 8, 2006).

6. Barbara Quint, "With OCLC's New Strategy, Is Earth's Largest Library in Sight?" Searcher (October 30, 2000), Available at: http://www.infotoday.com/newsbreaks/nbOO 1030-1 .htm (Accessed June 8, 2006).

7. John Markoff and Edward Wyatt, "Google is Adding Major Libraries into its Databases," New York Times (2004, September 14): Available at: http://www.nytimes.com/2004/12/14/technology/14google.html?ex=1141794000\&en=a 58fllae9e54b47b\&ei= 5070 (Accessed June 8, 2006).

8. Thomas Frey, "The Future of Libraries: Beginning the Great Transformation" DaVinci Institute, Available at: http://www. davinciinstitutexom/page.php? ID=120 (Accessed June 8, 2006).

9. Roy Tennant, "Life Beyond MARC: The Case for Revolutionary Change in Library Systems and Service," Speech at the Library of Congress (September 15, 2005), Available at: http://www. loc.gov/ today/cyberlc/feature_wdesc.php?rec=3774 (Accessed June 8, 2006).

10. "RLG to Combine with OCLC," Available at: http://www.oclc.org/news/releases/200618.htm (Accessed June 8, 2006).

11. "More Information on Consortia and their Services," Available at: http.V/www. library.yale.edu/consortia/icolcmembers.html (Accessed June 8, 2006).

12. "Z-Interop: A Z39.50 Interoperability Testbed Study," Available at: http://www.unt.edu/zinterop/index.htm (Accessed June 8, 2006).

13. "MARCedit," Available at: http://oregonstate.edu/ reeset/marcedit/ html/ (Accessed June 8, 2006). 